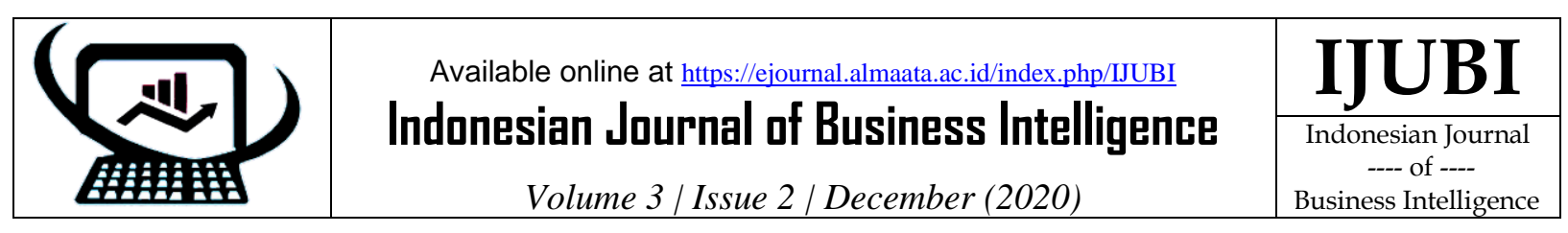

ANALISIS EFEKTIFITAS MEDIA PROMOSI TERHADAP PENERIMAAN MAHASISWA BARU (PMB)

Bayu Dwi Raharja ${ }^{1}$, Paulus Harsadi ${ }^{2}$

1 Program Studi Sistem Informasi Akuntansi, STMIK Sinar Nusantara,

2Program Studi Informatika, STMIK Sinar Nusantara,

bayudr@sinus.ac.id, paulusharsadi@sinus.ac.id

Jl. K H Samanhudi No 84 - 86 Surakarta

Keywords:

\section{New Student}

Admissions,

marketing, graphic

design, and

multimedia

\section{Kata Kunci:}

Penerimaan

Mahasiswa Baru, pemasaran, desain grafis, dan multimedia.

\section{Abstract}

The level of competition for new student admissions at tertiary institutions in the Central Java region for the last 5 years is quite high. STMIK Sinar Nusantara has also experienced the impact of competition, which can be seen through the decline in new students by an average of $20 \%$ in the last 5 years. This study aims to determine how much influence the promotional media has on the acceptance of new students. By collecting data from questionnaires that have been distributed to 69 parents of STMIK Sinar Nusantara students. Where these students entered college from batch 2015, 2016, 2017, 2018 and 2019. The promotional media studied included print media, namely posters, brochures and billboards. And electronic media, namely radio and websites, as well as other media through daily conversations. After the data is tested for validity, reliability test and classical assumption are processed to produce a regression equation. Hypothesis testing shows that the three independent variables studied, namely the print media (X1), electronic media (X2) and other media (X3) variables, have a positive effect on the dependent variable, namely New Student Admissions (Y). Through variable X1, it has a coefficient value of 0.990 , which means the effectiveness of print media has a positive influence on registrant interest $(\mathrm{Y})$, as well as variables $\mathrm{X} 2$ and $\mathrm{X} 3$, each of which has a coefficient value of $\mathrm{X} 2=0.787$ and $\mathrm{X} 3=0.626$.

\section{Abstrak}

Tingkat persaingan penerimaan mahasiswa baru pada perguruan tinggi di wilayah jawa tengah 5 tahun terakhir cukup tinggi. STMIK Sinar Nusantara juga mengalami dampak persaingan dapat dilihat melalui penurunan mahasiswa baru rata - rata $20 \%$ dalam 5 tahun terakhir. Penelitian ini bertujuan untuk mengetahui seberapa besar pengaruh media promosi terhadap penerimaan Mahasiswa Baru. Dengan cara mengumpulkan data dari kuesioner yang telah dibagikan kepada 69 orang tua mahasiswa STMIK Sinar Nusantara. Dimana mahasiswa tersebut masuk kuliah dari angkatan 2015, 2016, 2017, 2018 dan 2019. Media promosi yang diteliti meliputi media cetak yaitu poster, brosur dan baliho. Dan media elektronik yaitu radio dan website, begitu juga media lain melalui percakapan sehari - hari.

Setelah data di uji validitas, uji reliabilitas dan uji asumsi klasik diolah menghasilkan persamaan regresi. Dari pengujian hipotesis menunjukkan bahwa tiga variabel independen yang di teliti yaitu variabel media cetak (X1), media elektronik $(X 2)$ dan media lainnya $(X 3)$ berpengaruh positif terhadap variabel dependen yaitu Penerimaan Mahasiswa Baru (Y). Melalui variabel X1 memiliki nilai koefisiensi sebesar 0,990 yang berarti efektifitas media cetak mempunyai pengaruh positif terhadap minat pendaftar $(\mathrm{Y})$, begitu juga 
dengan variabel $\mathrm{X} 2$ dan $\mathrm{X} 3$ yang masing masing mempunyai nilai koefisien $\mathrm{X} 2=0,787$ dan $\mathrm{X} 3=0,626$.

\section{Pendahuluan}

Persaingan antara perguruan tinggi di jawa tengah semakin ketat, keinginan dari masyarakat terhadap jaminan mutu dari suatu perguruan tinggi adalah faktor terjadinya persaingan. Salah satu bentuk pertanggungjawaban perguruan tinggi terhadap masyarakat adalah memberikan kualitas terbaik, yang dinyatakan dalam bentuk Akreditasi Institusi. Dimana dalam pengurusan akreditasi tersebut terdapat beberapa faktor penentu, salah satunya proses penerimaan mahasiswa baru.

Penerimaan mahasiswa baru merupakan salah satu kegiatan utama yang dilakukan perguruan tinggi setiap tahunnya. Promosi biasanya dilakukan dengan berbagai cara dengan mempertimbangkan berbagai aspek untuk menarik minat siswa. Keberhasilan promosi ditentukan dari banyak atau sedikit jumlah siswa yang masuk sebagai mahasiswa ke perguruan tinggi tersebut. Ada berbagai bentuk media promosi yang dapat dilakukan, antara lain: Media cetak seperti brosur, pamflet, dan baliho. Media elektronik seperti radio, TV dan internet. Media lainnya yaitu percakapan sehari - hari maupun ada bagian keluarga yang kuliah di STMIK Sinar Nusantara.

Promosi memiliki tujuan untuk menyampaikan pesan, dimana pesan tersebut itulah yang seharusnya bisa mempengaruhi audience dengan baik. Dan tidak hanya pesan namun juga tampilan yang menarik, sehingga pesan yang disampaikan dapat menarik minat masyarakat hingga menimbulkan ketertarikan atau hanya sekedar mengetahui STMIK Sinar Nusantara.

Dari pemaparan diatas, dapat dirumuskan sebagai berikut media promosi apa yang lebih efektif digunakan saat penerimaan mahasiswa baru.

\section{Landasan Teori}

Teori - teori yang relevan dan mendukung dalam penelitian ini meliputi pemasaran, media, analisa dan regresi linier.
1. Promosi merupakan unsur kunci dalam penerimaan mahasiswa baru, dan promosi yang paling baik adalah dilakukan mahasiswa sendiri yang merasa puas. Dengan demikian, promosi perlu ditangani secara cermat. Bukan hanya menyangkut bagaimana berkomunikasi dengan pelanggan akan tetapi juga menyangkut seberapa besar biaya yang dikeluarkan. Promosi adalah arus informasi atau persuasi satu arah yang dibuat untuk mengarahkan seseorang atau organisasi kepada tindakan yang menciptakan pertukaran dalam pemasaran (Nikels dalam Swastha \& Irwan, 2008)

2. Media Promosi

Menurut kamus besar bahasa Indonesia, media adalah alat (sarana) komunikasi seperti koran, majalah, radio, televise, poster dan spanduk. Secara etimologi kata media merupakan bentuk jamak dari medium yang berasal dari bahasa latin medius yang berarti tengah. Dari pengertian tersebut maka dapat mengarah pada sesuatu yang mengantar atau meneruskan informasi pesan antara sumber (pemberi pesan) dan penerima pesan. Media juga dapat diartikan sebagai suatu bentuk dan saluran yang dapat digunakan dalam suatu proses penyajian informasi.

3. Analisa

Analisis adalah penyelidikan terhadap suatu peristiwa (perbuatan, karangan dan sebagainya) untuk mendapatkan fakta yang tepat (asal usul, sebab, penyebab sebenarnya, dan sebagainya)(Salim, 2002).

Analisa merupakan kegiatan menghitung data agar dapat disajikan secara sistematis (Priyatno, 2010).

4. Regresi Linier

Regresi secara umum adalah sebuah alat statistik yang memberikan penjelasan tentang pola hubungan (model) antara dua variabel atau lebih. Analisis Regresi digunakan untuk membangun persamaan 
dan menggunakan persamaan tersebut untuk membuat perkiraan (prediction).

\section{Metode}

Penelitian ini dilaksanakan di STMIK Sinar Nusantara Surakarta dengan membagikan kuesioner ke mahasiswa yang berlokasi di berbagai daerah di jawa tengah.

1. Variabel Penelitian

Variabel yang duigunakan dalam penelitian ini adalah:

a. Variabel Independen (media promosi)

- Efektifitas Media Cetak

- Efektifitas Media Elektornik

- Efektifitas Media Lainnya

b. Variabel Dependen (minat siswa)

2. Sumber Data

a. Data Primer

Data primer merupakan data yang diperoleh langsung dari objek penelitian di sini (STMIK Sinar Nusantara). Obyek penelitian merupakan mahasiswa baru dari tahun 2015 hingga 2019.

- Media Promosi apa saja yang digunakan

- Pendapat mahasiswa baru terhadap media promosi yang ada

b. Data Sekunder

Data sekunder diperoleh dari luar objek penelitian yang masih ada keterkaitannya dengan masalah yang diletili dan di literature. Data sekunder yang diperlukan meliputi:

- Penelitian ilmiah/ jurnal ilmiah yang membahas mengenai media promosi.

- Referensi dari berbagai buku pemasaran atau promosi dan PMB.

3. Teknik Pengumpulan Data

Pengambilan data mengikuti ukuran suharsimi Arikunto (1998)[2], yaitu bila subjek kurang dari 100, maka lebih baik diambil semua, sehingga merupakan penelitian populasi. Dan jika jumlah lebih dari 100, dapat diambil Antara 10 - 15\%, 20 - $25 \%$ atau lebih. Jumlah mahasiswa baru Antara 2015 - 2019 berjumlah 690 mahasiswa. Sehingga peneliti menetapkan besar subyek penelitian yaiyu 10\% dari 690 didapatkan subyek sebanyak 69 mahasiswa. Untuk mendapat data primer, digunakan teknik wawancara dan survey (observasi) dengan menggunakan kuesioner di lembar kertas kerja berkaitan dengan masalah yang diteliti. Kuesioner di isi orang tua siswa maupun siswa tersebut.

4. Analisa Data dan Penarikan Kesimpulan

Dalam menganalisa hasil penelitian digunakan analisa kuantitatif yaitu analisa yang dilakukan terhadap data yang berwujud angka, dengan cara menjumlahkan, mengklasifikasikan, mentabulasikan dan selanjutnya dilakukan penghitungan dengan menggunakan data statistic.

berikutnya adalah menganalisa dengan analisa kuantitatif secara deskriptif analisis yang sebelumnya telah ditentukan presentasenya dengan menggunakan rumus distribusi frekuensi:

$$
M=\frac{\sum X}{N}
$$

Keterangan :

M : Mean

$\mathrm{X} \quad$ : Nilai

$\mathrm{N}$ : Jumlah Subjek (Responden)

Selanjutnya membandingkan skor dari hasil pengumpulan tersebut. Peneliti menggunakan rumus Pearson Product Moment untuk melihat hubungan media promosi dengan PMB dengan pemahaman konsep.

Rumus Pearson Product Moment:

$$
r x y=\frac{n \sum x y-\left(\sum x\right)\left(\sum y\right)}{\sqrt{\left[N \sum x^{2}-\left(\sum x\right)^{2}\right]\left[N \sum x^{2}-\left(\sum y\right)^{2}\right]}}
$$

[2]

Keterangan:

rxy : koefisiensi korelasi product moment

$$
\begin{array}{ll}
\mathrm{x} & \text { : nilai } \\
\mathrm{y} x y & \text { : jumlah nilai } \\
\sum x & \text { :jumlah hasil nilai } \mathrm{x} \text { dan } \mathrm{y} \\
\sum y & \text { : jumlah nilai } \mathrm{x} \\
\mathrm{N} & \text { : banyaknya responden. }
\end{array}
$$

IJUBI - VOL 3 No. 2 (2020) : 38 - 47 


\section{Hasil dan Pembahasan}

Pada penelitian yang menggunakan analisis regresi dengan model tersebut, maka sebelum dilakukan pengujian hipotesis maka setiap variabel yang diteliti harus dilakukan Uji Validitas dan Uji Reliabilitas terlebih dahulu.

Tabel 1. Uji Validitas tiap Item Pertanyaan untuk Variabel Efektivitas Media Cetak (X1)

\begin{tabular}{|c|c|c|c|c|c|c|c|c|}
\hline & & $\begin{array}{c}\text { Brosur } \\
\text { Menarik }\end{array}$ & $\begin{array}{c}\text { Brosur } \\
\text { Informatif }\end{array}$ & $\begin{array}{l}\text { Poster } \\
\text { Menarik }\end{array}$ & $\begin{array}{c}\text { Poster } \\
\text { Informatif }\end{array}$ & $\begin{array}{c}\text { Baliho } \\
\text { Menarik }\end{array}$ & $\begin{array}{l}\text { Baliho } \\
\text { Informatif }\end{array}$ & $\begin{array}{c}\text { Efektifitas Media } \\
\text { cetak }\end{array}$ \\
\hline \multirow[t]{3}{*}{$\begin{array}{l}\text { Brosur } \\
\text { Menarik }\end{array}$} & $\begin{array}{l}\text { Pearson } \\
\text { Correlation }\end{array}$ & 1 & $.578^{* *}$ & $.690^{* *}$ & $.505^{*+*}$ & $.380^{* *}$ & $.500^{*+}$ & $.778^{*+*}$ \\
\hline & Sig. (2-tailed) & & .000 & .000 & .000 & .000 & .000 & .000 \\
\hline & $\mathrm{N}$ & 69 & 69 & 69 & 69 & 69 & 69 & 69 \\
\hline \multirow[t]{3}{*}{$\begin{array}{l}\text { Brosur } \\
\text { informative }\end{array}$} & $\begin{array}{l}\text { Pearson } \\
\text { Correlation }\end{array}$ & & 1 & $.381^{\star *}$ & $.548^{+*+}$ & $.210^{* *}$ & $.482^{2+}$ & $.674^{*+4}$ \\
\hline & Sig. (2-tailed) & .000 & & .001 & .000 & .083 & .000 & . 000 \\
\hline & $\mathrm{N}$ & 69 & 69 & 69 & 69 & 69 & 69 & 69 \\
\hline \multirow[t]{3}{*}{$\begin{array}{l}\text { Poster } \\
\text { Menarik }\end{array}$} & $\begin{array}{l}\text { Pearson } \\
\text { Correlation }\end{array}$ & $.690^{* *}$ & .381** & 1 & $.705^{*+*}$ & $.624^{* *}$ & $.650^{*+*}$ & $.876^{* *}$ \\
\hline & Sig. (2-tailed) & .000 & .001 & & .000 & .000 & .000 & .000 \\
\hline & $\mathrm{N}$ & 69 & 69 & 69 & 69 & 69 & 69 & 69 \\
\hline \multirow[t]{3}{*}{$\begin{array}{l}\text { Poster } \\
\text { Informatif }\end{array}$} & $\begin{array}{l}\text { Pearson } \\
\text { Correlation }\end{array}$ & $.505^{* *}$ & $.548^{* *}$ & $.705^{\star *}$ & 1 & $.371^{\star *}$ & $.670^{* *}$ & $.816^{*+4}$ \\
\hline & Sig. (2-tailed) & .000 & .000 & .000 & & .002 & .000 & . 000 \\
\hline & $\mathrm{N}$ & 69 & 69 & 69 & 69 & 69 & 69 & 69 \\
\hline \multirow[t]{3}{*}{$\begin{array}{l}\text { Baliho } \\
\text { menarik }\end{array}$} & $\begin{array}{l}\text { Pearson } \\
\text { Correlation }\end{array}$ & $.380^{*+}$ & $210^{* *}$ & $.624^{* *}$ & $.371^{* *}$ & 1 & $.616^{*+}$ & $.690^{* *}$ \\
\hline & Sig. (2-tailed) & .000 & .083 & .000 & .002 & & .000 & .000 \\
\hline & $\mathrm{N}$ & 69 & 69 & 69 & 69 & 69 & 69 & 69 \\
\hline \multirow[t]{3}{*}{$\begin{array}{l}\text { Baliho } \\
\text { informatif }\end{array}$} & $\begin{array}{l}\text { Pearson } \\
\text { Correlation }\end{array}$ & $.500^{*+*}$ & $.482^{* *}$ & $.650^{*+*}$ & $.670^{* *}$ & $.616^{* *}$ & 1 & $.837^{4+*}$ \\
\hline & Sig. (2-tailed) & .000 & .000 & .000 & .000 & .000 & & .000 \\
\hline & $\mathrm{N}$ & 69 & 69 & 69 & 69 & 69 & 69 & 69 \\
\hline \multirow[t]{3}{*}{$\begin{array}{l}\text { Efektifitas } \\
\text { Media Cetak }\end{array}$} & $\begin{array}{l}\text { Pearson } \\
\text { Correlation }\end{array}$ & $.778^{* *}$ & $.674^{* *}$ & $.876^{* *}$ & $.816^{*+}$ & $.690^{* *}$ & $.837^{*+}$ & 1 \\
\hline & Sig. (2-tailed) & .000 & .000 & .000 & .000 & .000 & .000 & \\
\hline & $\mathrm{N}$ & 69 & 69 & 69 & 69 & 69 & 69 & 69 \\
\hline
\end{tabular}

Berdasarkan data tersebut pada Tabel 1, dengan melihat nilai Pearson Correlation antara pertanyaan apakah tertarik mencari informasi lebih lanjut mengenai setelah melihat Brosur (Brosur Menarik/P1) dengan efektivitas media cetak(X1), pertanyaan Brosur Informatif (P2) dengan efektivitas media cetak(X1), pertanyaan Poster Menarik (P3) dengan efektivitas media cetak(X1),

41 "Bayu Dwi Raharja" pertanyaan Poster Informatif (P4) dengan efektivitas media cetak(X1), pertanyaan Baliho Menarik (P5) dengan efektivitas media cetak(X1), dan pertanyaan Baliho Informatif (P6) dengan efektivitas media cetak(X1) berada pada taraf signifikansi korelasi sebesar 0,01 (lihat tanda bintang) dan nilai sig. (2-tailed) $=$ $0,000<0,01$ maka dapat dinyatakan bahwa item-item pertanyaan untuk Variabel 
efektivitas media cetak(X1) dinyatakan valid. Semua data pada pertanyaan tersebut dapat digunakan untuk olah data berikutnya.

Tabel 2. Uji Validitas tiap Item Pertanyaan untuk Variabel Efektivitas Media Elektronik (X2)

\begin{tabular}{|c|c|c|c|c|c|c|}
\hline & & $\begin{array}{c}\text { Bahasa Iklan } \\
\text { Radio Informatif }\end{array}$ & $\begin{array}{l}\text { Iklan Radio } \\
\text { Menarik }\end{array}$ & $\begin{array}{l}\text { Website } \\
\text { Informatif }\end{array}$ & $\begin{array}{l}\text { Website } \\
\text { Menarik }\end{array}$ & $\begin{array}{c}\text { Efektivitas Media } \\
\text { Elektronik }\end{array}$ \\
\hline \multicolumn{2}{|c|}{$\begin{array}{l}\text { Bahasa Iklan Pearson } \\
\text { Radio Informatif Correlation }\end{array}$} & \multirow[b]{3}{*}{69} & $.780^{* *}$ & -.005 & .167 & $.716^{*}$ \\
\hline & Sig. (2-tailed) & & .000 & .964 & .171 & .00 \\
\hline & $\mathrm{N}$ & & 69 & 69 & 69 & 6 \\
\hline $\begin{array}{ll}\text { Iklan } & \text { Radio } \\
\text { Menarik } & \end{array}$ & $\begin{array}{l}\text { Pearson } \\
\text { Correlation }\end{array}$ & & 1 & .095 & .226 & $.770^{*}$ \\
\hline & Sig. (2-tailed) & .000 & & .438 & .062 & .000 \\
\hline & $\mathrm{N}$ & 69 & 69 & 69 & 69 & 6 \\
\hline $\begin{array}{l}\text { Website } \\
\text { Informatif }\end{array}$ & $\begin{array}{l}\text { Pearson } \\
\text { Correlation }\end{array}$ & -.005 & .095 & 1 & $.628^{* *+}$ & \\
\hline & Sig. (2-tailed) & .964 & .438 & & .000 & .00 \\
\hline & $\mathrm{N}$ & 69 & 69 & 69 & 69 & 6 \\
\hline Website Menarik & $\begin{array}{l}\text { Pearson } \\
\text { Correlation }\end{array}$ & .167 & .226 & $.628^{* *}$ & 1 & \\
\hline & Sig. (2-tailed) & . 171 & .062 & .000 & & .006 \\
\hline & $\mathrm{N}$ & 69 & 69 & 69 & 69 & 6 \\
\hline $\begin{array}{l}\text { Efektivitas } \\
\text { Media Elektronik }\end{array}$ & $\begin{array}{l}\text { Pearson } \\
\text { Correlation }\end{array}$ & $.716^{* *}$ & $.770^{*+*}$ & $.593^{* *}$ & $.709^{*+*}$ & \\
\hline & Sig. (2-tailed) & .000 & .000 & .000 & .000 & \\
\hline & $\mathrm{N}$ & 69 & 69 & 69 & 69 & \\
\hline
\end{tabular}

Berdasarkan data tersebut pada Tabel 2, dengan melihat nilai Pearson Correlation antara pertanyaan apakah tertarik mencari informasi lebih lanjut mengenal setelah mendengar iklan radio (Bahasa iklan radio informatif / P1) dengan efektektivitas media elektronik (X2), iklan radio menarik (P2) dengan efektivitas media elektronik (X2), website informatif (P3) dengan efektivitas media elektornik (X2), website menarik (P4) dengan efektivitas media elektronik (X2) berada pada taraf signifikansi korelasi sebesar 0,01 (lihat tanda bintang) dan nilai sig. (2-tailed) $=0,000<0,01$ maka dapat dinyatakan bahwa item-item pertanyaan untuk variabel efektivitas media elektronik (X2) dinyatakan valid. Semua data pada pertanyaan tersebut dapat digunakan untuk olah data berikutnya.
Tabel 3. Uji Validitas tiap Item Pertanyaan untuk Variabel Efektivitas Media Lainnya (X3)

\begin{tabular}{|c|c|c|c|c|c|}
\hline & & $\begin{array}{l}\text { Info dari } \\
\text { Alumni }\end{array}$ & $\begin{array}{c}\text { Info dari } \\
\text { Guru }\end{array}$ & $\begin{array}{l}\text { Info dari } \\
\text { Anggota } \\
\text { Keluarga }\end{array}$ & $\begin{array}{l}\text { Efektivitas } \\
\text { Media } \\
\text { Promosi Lain }\end{array}$ \\
\hline $\begin{array}{l}\text { Info dari } \\
\text { Alumni }\end{array}$ & $\begin{array}{l}\text { Pearson } \\
\text { Correlation } \\
\text { Sig. (2-tailed) } \\
\mathrm{N}\end{array}$ & 1 & $\begin{array}{r}.646^{*+} \\
.000 \\
69\end{array}$ & $\begin{array}{r}.177 \\
.146 \\
69\end{array}$ & $\begin{array}{r}.728^{*+} \\
.000 \\
69\end{array}$ \\
\hline Info dari Guru & $\begin{array}{l}\text { Pearson } \\
\text { Correlation } \\
\text { Sig. (2-tailed) } \\
\mathrm{N}\end{array}$ & $\begin{array}{r}.646^{+*} \\
.000 \\
69\end{array}$ & 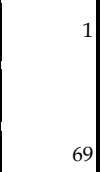 & $\begin{array}{r}.191 \\
.115 \\
69\end{array}$ & $\begin{array}{r}.723^{*+} \\
.000 \\
69\end{array}$ \\
\hline $\begin{array}{ll}\text { Info } & \text { dari } \\
\text { Anggota } & \\
\text { Keluarga } & \end{array}$ & $\begin{array}{l}\text { Pearson } \\
\text { Correlation } \\
\text { Sig. (2-tailed) } \\
\mathrm{N}\end{array}$ & $\begin{array}{r}.177 \\
.146 \\
69\end{array}$ & $\begin{array}{l}.191 \\
.115 \\
69\end{array}$ & 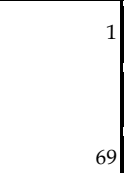 & $\begin{array}{r}.750^{*+} \\
.000 \\
69\end{array}$ \\
\hline $\begin{array}{l}\text { Efektivitas } \\
\text { Media Promosi } \\
\text { Lain }\end{array}$ & $\begin{array}{l}\text { Pearson } \\
\text { Correlation } \\
\text { Sig. (2-tailed) } \\
\mathrm{N}\end{array}$ & $\begin{array}{r}.728^{\star *} \\
.000 \\
69\end{array}$ & $\begin{array}{r}.723^{* *} \\
.000 \\
69\end{array}$ & $\begin{array}{r}.750^{* *} \\
.000 \\
69\end{array}$ & 1 \\
\hline
\end{tabular}

IJUBI - VOL 3 No. 2 (2020) : 38 - 47 
Berdasarkan data tersebut pada Tabel 3, dengan melihat nilai Pearson Correlation antara pertanyaan apakah tertarik mencari informasi lebih lanjut mengenal setelah mendapat info dari alumni (P1) dengan efektektivitas media lainnya (X3), info dari guru (P2) dengan efektivitas media lainnya (X3), info dari anggota keluarga (P3) dengan efektivitas media lainnya (X3) berada pada taraf signifikansi korelasi sebesar 0,01 (lihat tanda bintang) dan nilai sig. (2-tailed) $=0,000$ $<0,01$ maka dapat dinyatakan bahwa itemitem pertanyaan untuk variabel efektivitas media lainnya (X3) dinyatakan valid. Semua data pada pertanyaan tersebut dapat digunakan untuk olah data berikutnya.

Tabel 4. Uji Validitas tiap Item Pertanyaan untuk Variabel Minat Mendaftar

\begin{tabular}{|c|c|c|c|c|c|c|c|c|}
\hline $\begin{array}{l}\text { Minat Mendaftar } \\
\text { Pengaruh }\end{array}$ & & $\begin{array}{l}\text { Desain } \\
\text { Brosur }\end{array}$ & $\begin{array}{l}\text { Desain } \\
\text { Poster }\end{array}$ & $\begin{array}{l}\text { Desain } \\
\text { Baliho }\end{array}$ & $\begin{array}{l}\text { Info } \\
\text { Radio }\end{array}$ & \begin{tabular}{|l|} 
Desain \\
Website
\end{tabular} & $\begin{array}{c}\text { Info Pihak } \\
\text { lain }\end{array}$ & $\begin{array}{c}\text { Penerimaan } \\
\text { mahasiswa baru }\end{array}$ \\
\hline \multirow[t]{3}{*}{ Desain Brosur } & Pearson Correlation & 1 & $.689^{\star \star}$ & $.711^{* *}$ & .195 & .207 & .219 & $.760^{* *}$ \\
\hline & Sig. (2-tailed) & & .000 & .000 & .109 & .088 & .070 & .0 \\
\hline & $\mathrm{N}$ & 69 & 69 & 69 & 69 & 69 & 69 & \\
\hline \multirow[t]{3}{*}{ Desain Poster } & Pearson Correlation & $.689^{*+*}$ & 1 & $.703^{* *}$ & $.269^{*}$ & .230 & $.320^{* *}$ & $.805^{*+}$ \\
\hline & Sig. (2-tailed) & .000 & & .000 & .025 & .058 & .007 & .00 \\
\hline & $\mathrm{N}$ & 69 & 69 & 69 & 69 & 69 & 69 & 69 \\
\hline \multirow[t]{3}{*}{ Desain Baliho } & Pearson Correlation & $.711^{* *}$ & $.703^{* *}$ & 1 & .178 & .152 & $.310^{* *}$ & $.773^{*+*}$ \\
\hline & Sig. (2-tailed) & .000 & .000 & & .143 & .214 & .010 & .000 \\
\hline & $\mathrm{N}$ & 69 & 69 & 69 & 69 & 69 & 69 & 69 \\
\hline \multirow[t]{3}{*}{ Info Radio } & Pearson Correlation & .195 & $.269^{*}$ & .178 & 1 & $.332^{* *}$ & .142 & $.517^{\star}$ \\
\hline & Sig. (2-tailed) & .109 & .025 & .143 & & .005 & .245 & .000 \\
\hline & $\mathrm{N}$ & 69 & 69 & 69 & 69 & 69 & 69 & \\
\hline \multirow[t]{3}{*}{ Desain Website } & Pearson Correlation & .207 & .230 & .152 & $.332^{* *}$ & 1 & $.297^{*}$ & $.468^{* *}$ \\
\hline & Sig. (2-tailed) & .088 & .058 & .214 & .005 & & .013 & .000 \\
\hline & $\mathrm{N}$ & 69 & 69 & 69 & 69 & 69 & 69 & 69 \\
\hline \multirow[t]{3}{*}{ Info Pihak Lain } & Pearson Correlation & .219 & $.320^{* *}$ & $.310^{* *}$ & .142 & $.297^{*}$ & 1 & $.521^{* *}$ \\
\hline & Sig. (2-tailed) & .070 & .007 & .010 & .245 & .013 & & 000 \\
\hline & $\mathrm{N}$ & 69 & 69 & 69 & 69 & 69 & 69 & 69 \\
\hline \multirow{3}{*}{\begin{tabular}{|l} 
Penerimaan \\
mahasiswa baru
\end{tabular}} & Pearson Correlation & $.760^{*+4}$ & $.805^{*+}$ & $.773^{*+}$ & $.517^{\text {t* }}$ & $.468^{* * t}$ & $.521^{* *}$ & \\
\hline & Sig. (2-tailed) & .000 & .000 & .000 & .000 & .000 & .000 & \\
\hline & $\mathrm{N}$ & 69 & 69 & 69 & 69 & 69 & 69 & 6 \\
\hline
\end{tabular}

Berdasarkan data tersebut pada Tabel 4, dengan melihat nilai Pearson Correlation antara pertanyaan apakah berminat mendaftar setelah melihat desain brosur (P1) dengan minat mendaftar $(\mathrm{Y})$, pengaruh desain poster (P2) dengan minat mendaftar (Y), pengaruh desain baliho (P3) dengan minat mendaftar $(\mathrm{Y})$, pengaruh info radio $(\mathrm{P} 4)$ dengan minat mendaftar $(\mathrm{Y})$, pengaruh desain website (P5) dengan minat mendaftar $(\mathrm{Y})$, pengaruh pihak lain (P6) dengan minat mendaftar $(Y)$ berada pada taraf signifikansi korelasi sebesar 0,01 (lihat tanda bintang) dan nilai sig. (2-tailed) $=$ $0,000<0,01$ maka dapat dinyatakan bahwa item-item pertanyaan untuk variabel minat mendaftar (Y) dinyatakan valid. Semua data pada pertanyaan tersebut dapat digunakan untuk olah data berikutnya.

Tabel 5. Uji Reliabilitas Variabel Efektivitas Media Cetak (X1)

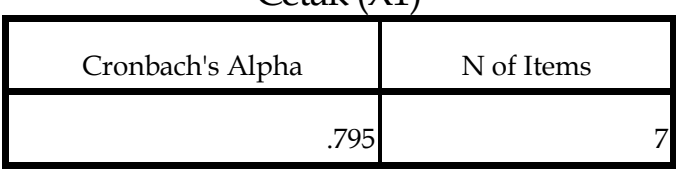


Tabel 6. Uji Reliabilitas Tiap Responden pada Tiap Pertanyaan Variabel Efektivitas Media Cetak (X1)

\begin{tabular}{|l|r|r|r|r|}
\hline & $\begin{array}{c}\text { Scale Mean } \\
\text { if Item } \\
\text { Deleted }\end{array}$ & $\begin{array}{c}\text { Scale } \\
\text { Variance if } \\
\text { Item } \\
\text { Deleted }\end{array}$ & $\begin{array}{r}\text { Corrected } \\
\text { Item-Total } \\
\text { Correlatio } \\
\mathrm{n}\end{array}$ & $\begin{array}{c}\text { Cronbach's } \\
\text { Alpha if } \\
\text { Item } \\
\text { Deleted }\end{array}$ \\
\hline Brosur Menarik & 39.7826 & 79.261 & .733 & .766 \\
Brosur Informatif & 40.0290 & 81.087 & .613 & .776 \\
Poster Menarik & 40.0435 & 74.807 & .843 & .746 \\
Poster Informatif & 40.2464 & 77.483 & .774 & .759 \\
Baliho Menarik & 39.8261 & 80.234 & .627 & .773 \\
Baliho Informatif & 40.3188 & 77.985 & .802 & .759 \\
Efektivitas & 21.8406 & 23.224 & 1.000 & .871 \\
Media Cetak & & & & \\
\hline
\end{tabular}

Berdasarkan Tabel 5, dapat dilihat bahwa nilai Cronbach's Alpha sebesar 0,795 sehingga item pertanyaan untuk mendapatkan nilai Variabel X1 dapat dikatakan reliable atau andal. Berdasarkan Tabel 7, konsistensi tiap pertanyaan pada variabel efektivitas media cetak tinggi. Berdasarkan Tabel 6, konsistensi responden menjawab tiap pertanyaan tinggi, baik pertanyaan Brosur Menarik (P1), Brosur Informatif (P2), Poster Menarik (P3), Poster Informatif (P4), Baliho Menarik (P5), dan Baliho Informatif (P6) nilai Cronbach Alfa lebih dari 0,600 .

Tabel 7. Kriteria Indeks Reliabilitas

\begin{tabular}{|l|l|l|}
\hline No & Interval & Kriteria \\
\hline $\mathbf{1}$ & $<0,200$ & Sangat rendah \\
\hline $\mathbf{2}$ & $0,200-0,399$ & Rendah \\
\hline $\mathbf{3}$ & $0,400-0,599$ & Cukup \\
\hline $\mathbf{4}$ & $0,600-0,799$ & Tinggi \\
\hline $\mathbf{5}$ & $0,800-1,000$ & Sangat Tinggi \\
\hline
\end{tabular}

Tabel 8. Uji Reliabilitas Variabel Efektivitas Media \begin{tabular}{|r|r|}
\multicolumn{2}{c}{ Elektronik (X2) } \\
\hline Cronbach's Alpha & N of Items \\
\hline .777 & \\
\hline
\end{tabular}
Tabel 9. Uji Reliabilitas Tiap Responden pada Tiap Pertanyaan Variabel Efektivitas Media Elektronik

(X2)

\begin{tabular}{|l|r|r|r|r|}
\hline & \multicolumn{1}{|c|}{$\begin{array}{c}\text { Scale } \\
\text { Mean if } \\
\text { Item } \\
\text { Deleted }\end{array}$} & $\begin{array}{c}\text { Scale } \\
\text { Variance if } \\
\text { Item } \\
\text { Deleted }\end{array}$ & $\begin{array}{r}\text { Corrected } \\
\text { Item-Total } \\
\text { Correlatio } \\
\mathrm{n}\end{array}$ & $\begin{array}{c}\text { Cronbach' } \\
\text { s Alpha if } \\
\text { Item } \\
\text { Deleted }\end{array}$ \\
\hline $\begin{array}{l}\text { Bahasa Iklan } \\
\text { Radio Informatif }\end{array}$ & 23.2899 & 25.444 & .604 & .737 \\
$\begin{array}{l}\text { Iklan Radio } \\
\text { Menarik ren }\end{array}$ & 23.1159 & 24.839 & .676 & .722 \\
$\begin{array}{l}\text { Website } \\
\text { Informatif } \\
\text { Website Menarik }\end{array}$ & 21.5217 & 25.900 & .604 & .741 \\
$\begin{array}{l}\text { Efektivitas Media } \\
\text { Elektronik }\end{array}$ & 12.7536 & 8.277 & 1.000 & .650 \\
\hline
\end{tabular}

Berdasarkan Tabel 8, dapat dilihat bahwa nilai Cronbach's Alpha sebesar 0,777 sehingga item pertanyaan untuk mendapatkan nilai Variabel X2 dapat dikatakan reliable atau andal. Berdasarkan Tabel 7, konsistensi tiap pertanyaan pada variabel efektivitas media elektonik tinggi. Berdasarkan Tabel 9, konsistensi responden menjawab tiap pertanyaan tinggi, baik pertanyaan Bahasa Iklan Radio informatif (P1), Iklan Radio Menarik (P2), Website Informatif (P3), Website Menarik (P4) nilai Cronbach Alfa lebih dari 0,600 .

Tabel 10. Uji Reliabilitas Variabel Efektivitas Media Lainnya (X3)

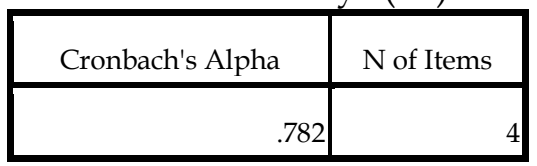

Tabel 11 Uji Reliabilitas Tiap Responden pada Tiap Pertanyaan Variabel Efektivitas Media Lainnya (X3)

\begin{tabular}{|l|r|r|r|r|}
\hline & $\begin{array}{c}\text { Scale Mean } \\
\text { if Item } \\
\text { Deleted }\end{array}$ & $\begin{array}{c}\text { Scale } \\
\text { Variance if } \\
\text { Item } \\
\text { Deleted }\end{array}$ & $\begin{array}{r}\text { Corrected } \\
\text { Item-Total } \\
\text { Correlation }\end{array}$ & $\begin{array}{r}\text { Cronbach } \\
\text { 's Alpha } \\
\text { if Item } \\
\text { Deleted }\end{array}$ \\
\hline Info dari Alumni & 16.4928 & 23.136 & .613 & .753 \\
Info dari Guru & 16.5217 & 23.841 & .621 & .761 \\
Info dari Anggota & 17.4928 & 19.489 & .557 & .745 \\
Keluarga & 10.1014 & 7.681 & 1.000 & .520 \\
Efektivitas Media & & & & \\
Promosi Lain & & & & \\
\hline
\end{tabular}


Berdasarkan Tabel 10, dapat dilihat bahwa nilai Cronbach's Alpha sebesar 0,782 sehingga item pertanyaan untuk mendapatkan nilai Variabel X3 dapat dikatakan reliable atau andal. Berdasarkan Tabel 7, konsistensi tiap pertanyaan pada variabel efektifitaf media lain tinggi. Berdasarkan Tabel 11, konsistensi responden menjawab tiap pertanyaan tinggi, baik pertanyaan Informasi dari alumni (P1), Info dari Guru (P2), info dari anggota keluarga (P3), nilai Cronbach Alfa lebih dari 0,600.

Tabel 12. Uji Reliabilitas Variabel Minat Mendaftar (Y)

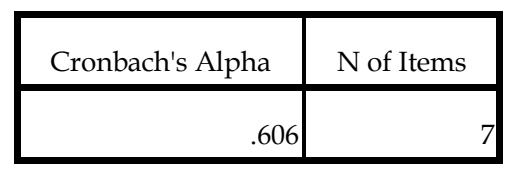

Tabel 13 Uji Reliabilitas Tiap Responden pada Tiap Pertanyaan Variabel Minat Mendaftar (Y)

\begin{tabular}{|c|c|c|c|c|}
\hline & $\begin{array}{l}\text { Scale } \\
\text { Mean if } \\
\text { Item } \\
\text { Deleted }\end{array}$ & $\begin{array}{c}\text { Scale } \\
\text { Variance if } \\
\text { Item } \\
\text { Deleted }\end{array}$ & $\begin{array}{c}\text { Corrected } \\
\text { Item-Total } \\
\text { Correlatio } \\
\mathrm{n}\end{array}$ & $\begin{array}{c}\text { Cronbach' } \\
\text { s Alpha if } \\
\text { Item } \\
\text { Deleted }\end{array}$ \\
\hline $\begin{array}{l}\text { Minat Mendaftar } \\
\text { Pengaruh Desain } \\
\text { Brosur }\end{array}$ & 59.0290 & 138.117 & .726 & .552 \\
\hline $\begin{array}{l}\text { Minat Mendaftar } \\
\text { Pengaruh Desain } \\
\text { Poster }\end{array}$ & 59.3333 & 136.225 & .780 & .544 \\
\hline $\begin{array}{l}\text { Minat Mendaftar } \\
\text { Pengaruh Desain } \\
\text { Baliho }\end{array}$ & 59.3623 & 136.411 & .737 & .546 \\
\hline $\begin{array}{l}\text { Minat Mendaftar } \\
\text { Pengaruh Info } \\
\text { Radio }\end{array}$ & 59.3623 & 141.234 & .457 & .572 \\
\hline $\begin{array}{l}\text { Minat Mendaftar } \\
\text { Pengaruh Desain } \\
\text { Website }\end{array}$ & 58.6087 & 147.095 & .433 & .589 \\
\hline $\begin{array}{l}\text { Minat Mendaftar } \\
\text { Pengaruh Info } \\
\text { Pihak Lain }\end{array}$ & 58.5217 & 145.665 & .474 & .584 \\
\hline $\begin{array}{l}\text { Penerimaan } \\
\text { Mahasiswa Baru }\end{array}$ & 21.4348 & 19.220 & .966 & .743 \\
\hline
\end{tabular}

Berdasarkan Tabel 12, dapat dilihat bahwa nilai Cronbach's Alpha sebesar 0,606 sehingga item pertanyaan untuk mendapatkan nilai Variabel Y dapat dikatakan reliable atau andal. Berdasarkan Tabel 7, konsistensi tiap pertanyaan pada variabel minat mendaftar. Berdasarkan Tabel 13, konsistensi responden 45 "Bayu Dwi Raharja" menjawab tiap pertanyaan cukup, baik pertanyaan Minat mendaftar pengaruh desain brosur(P1), minat mendaftar pengaruh desain poster (P2), minat mendaftar pengaruh desain baliho (P3), minat mendaftar pengaruh info radio (P4), minat mendaftar pengaruh desain website (P5), minat mendaftar pengaruh info pihak lain (P6) nilai Cronbach Alfa kurang dari 0,600 .

Tabel 14 . Koefisien Regresi Berganda

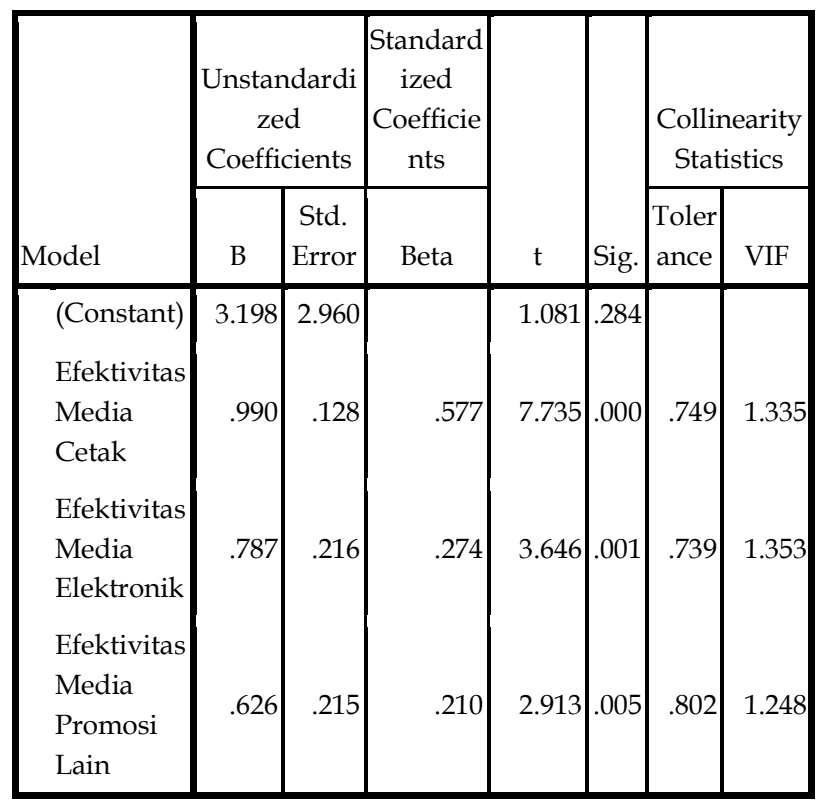

Berdasarkan Tabel 14 merupakan hasil pengolahan data analisis regresi linier, persamaan regresi yang dibentuk adalah : $Y$ $=3,198+0,990 X 1+0,787$ X2 + 0,626 X3. Persamaan regresi linier tersebut memberikan gambaran bahwa:

a. Variabel Efektivitas media cetak (X1) mempunyai nilai koefisien regresi sebesar 0,990 yang berarti Efektivitas media cetak mempunyai pengaruh positif terhadap Minat Mendaftar (Y), yaitu jika terjadi kenaikan efektivitas media cetak maka akan meningkatkan minat Mendaftar;

b. Variabel Efektivitas Media Elektronik (X2) mempunyai nilai koefisien regresi sebesar 0,787 yang berarti Stress Organisasi mempunyai pengaruh positif terhadap Minat Mendaftar (Y), yaitu jika terjadi kenaikan Efektivitas Media 
Elektronik maka akan meningkatkan minat Mendaftar;

c. Variabel Efektivitas Media Lainnya(X3) mempunyai nilai koefisien regresi sebesar 0,626 yang berarti Efektivitas Media Lainnyamempunyai pengaruh positif terhadap Minat Mendaftar (Y), yaitu jika terjadi kenaikan Efektivitas Media Lainnya maka akan meningkatkan minat Mendaftar;

d. Konstanta mempunyai nilai 3,198 yang artinya jika variabel X1, X2, dan X3 dalam mempunyai nilai nol atau tidak ada maka kinerja sebesar 3,198 dan nilai tersebut merupakan pengaruh dari variabel lain yang tidak dimasukkan dalam model regresi linier atau tergabung dalam Variabel Penggangu (e).

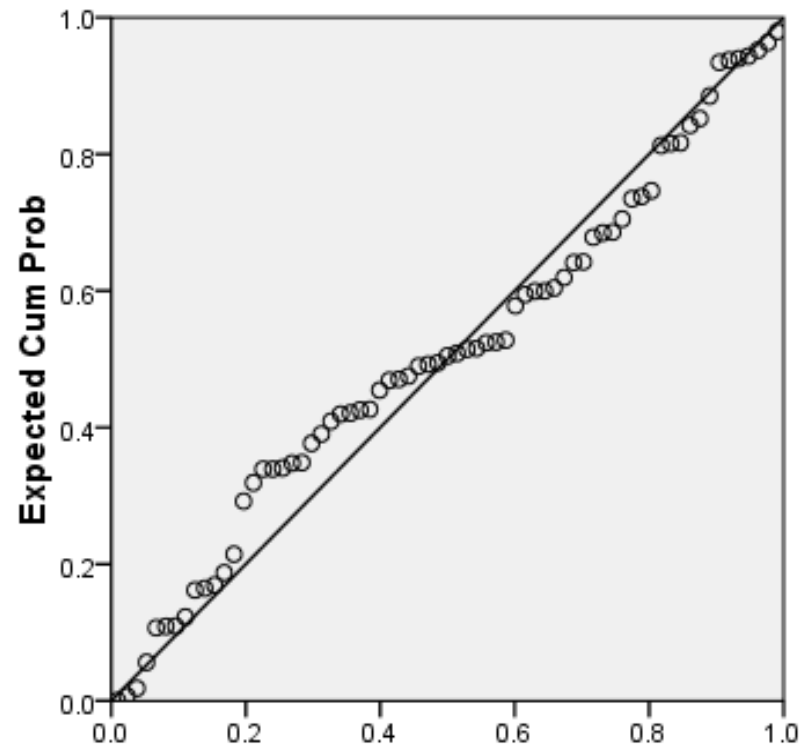

Gambar 1. Pola Grafik lurus persamaan regresi berganda

Berdasarkan Gambar 1.

$\mathrm{Y}=3,198+0,990 \mathrm{X} 1+0,787 \mathrm{X} 2+0,626 \mathrm{X} 3$

Dapat digunakan untuk peramalan variabel minat mendaftar jika diketahui variabel efektivitas media cetak, efektivitas media elektronik, dan efektivitas media promosi lainnya.

\section{Kesimpulan dan Saran}

Dari hasil pembahasan di atas pada tabel 14 dapat ditarik kesimpulan bahwa menggunakan media cetak memiliki 46 "Bayu Dwi Raharja" koefisiensi regresi sebesar 0,990 dimana dapat diartikan media cetak memiliki pengaruh positif terhadap penerimaan mahasiswa baru. Demikian juga dengan menggunakan media elektonik dan media lainnya, meskipun lebih kecil koefisiensi segresinya.

Untuk penelitian selanjutnya bisa mengembangkan dengan mencari faktor lain yang dapat mempengaruhi minat siswa dalam menentukan perguruan tinggi.

\section{Referensi}

[1] Sutrisno Hadi, "Metodologi Research 2". Yogyakarta : Andi Offset. 2004

[2] Arikunto, Suharsimi. "Prosedur Penelitian: suatu pendekatan Praktis", ed Revisi IV. Yogyakarta, Rineka Cipta. 1999

[3] Muth'ah Amani. "Analisis pengaruh effektifitas Iklan Celana jins merek lea terhadap keyakinan membeli konsumen dalam rangka meningkatkan Loyalitas Pelanggan (Studi kasus di kota Semarang)." Semarang. 2002

[4] Puspitadari, intan. "Factor - factor yang mempengaruhi Efektifitas Iklan dalam Menumbuhkan Brand Awareness." Semarang : Program Studi Magister Manajemen - Universitas Diponegoro. 2009

[5] Shim, Terence A. "Periklanan Promosi Aspek Tambahan Komunikasi Pemasaran Terpadu”. Jakarta : Penerbit Erlangga. 2003.

[6] Simamora, Bilson. "Analisis Multivariat Pemasaran". Jakarta : PT. Gramedia Pustaka Utama. 2005.

[7] Sudijono, Anas. "Pengantar STatistik Pendidikan”. Jakarta : Rajawali Pers. 2001.

[8] Sudjana. "Metode Statistik. Bandung : Tarsito". 1996.

[9] Budianto. A, Basari. M A, Hernawati. "Pengaruh biaya promosi dan kualitas SDM terhadap jumlah mahasiswa baru di fakultas ekonomi Universitas Galuh Ciamis". Jurnal ilmu manajemen. 2014 
[10] Sugiyanto, "Metode Penelitian kuantitatif, kualitatif, dan R\&D". Bandung: Alfabeta, CV. 2017. 